Article

\title{
On Viscous Flow in Glass-Forming Organic Liquids
}

\author{
Michael I. Ojovan 1,2(1) \\ 1 Department of Materials, Imperial College London, South Kensington Campus, Exhibition Road, \\ London SW7 2AZ, UK; m.ojovan@imperial.ac.uk or m.i.ojovan@gmail.com; Tel.: +44-747-828-9098 \\ 2 Department of Radiochemistry, Moscow State University Named after M.V. Lomonosov, Leninskie Gory 1, \\ Bd.3, 119991 Moscow, Russia
}

Academic Editors: Carmelo Corsaro and Enza Fazio

Received: 22 July 2020; Accepted: 1 September 2020; Published: 3 September 2020

check for updates

\begin{abstract}
The two-exponential Sheffield equation of viscosity $\eta(T)=A_{1} \cdot T \cdot\left[1+A_{2} \cdot \exp \left(H_{m} / R T\right)\right]$. $\left[1+\mathrm{C} \cdot \exp \left(\mathrm{H}_{\mathrm{d}} / \mathrm{RT}\right)\right]$, where $\mathrm{A}_{1}, \mathrm{~A}_{2}, \mathrm{H}_{\mathrm{m}}, \mathrm{C}$, and $\mathrm{H}_{\mathrm{m}}$ are material-specific constants, is used to analyze the viscous flows of two glass-forming organic materials-salol and $\alpha$-phenyl-o-cresol. It is demonstrated that the viscosity equation can be simplified to a four-parameter version: $\left.\eta(\mathrm{T})=\mathrm{A} \cdot \mathrm{T} \cdot \exp \left(\mathrm{H}_{\mathrm{m}} / \mathrm{RT}\right)\right] \cdot\left[1+\mathrm{C} \cdot \exp \left(\mathrm{H}_{\mathrm{d}} / \mathrm{RT}\right)\right]$. The Sheffield model gives a correct description of viscosity, with two exact Arrhenius-type asymptotes below and above the glass transition temperature, whereas near the $T_{g}$ it gives practically the same results as well-known and widely used viscosity equations. It is revealed that the constants of the Sheffield equation are not universal for all temperature ranges and may need to be updated for very high temperatures, where changes occur in melt properties leading to modifications of $\mathrm{A}$ and $\mathrm{H}_{\mathrm{m}}$ for both salol and $\alpha$-phenyl-o-cresol.
\end{abstract}

Keywords: glass-forming liquids; viscous flow; viscosity; activation energy; glass transition temperature

\section{Introduction}

The salient feature characterizing a supercooled liquid is the dramatic increase of viscosity $\eta(T)$ with decreasing temperature $\mathrm{T}$, which may encompass some 15 orders of magnitude over a temperature range of almost several hundred $\mathrm{K}$ [1-7]. The interest in analyzing the viscous flow in glass-forming materials is not diminishing, with many novel findings having occurred over the last decade [8-22]. There are many theoretical models that can describe the viscous flow of glass-forming materials, which provide reasonably exact descriptions of viscosity-temperature relationships [1-22]. Apart from the clear physical parameters used in the models, one of important features of the models is the asymptotic description of viscosities far from the transformation range, e.g., near the glass transition temperature $\mathrm{T}_{\mathrm{g}}$. It is well-known that at high and low temperatures, the viscosities of amorphous materials have an Arrhenius-type behavior $\eta(T)=A \cdot T \cdot \exp (\mathrm{Q} / \mathrm{RT})$, a fact that is widely used in practice. The deviation from the Arrhenius-type behavior can be described by the activation energy of the viscous flow $Q(T)$, dependent on temperature $T$. $Q(T)$ changes from its highest value $Q_{H}$ typical for low temperatures $\mathrm{T}<\mathrm{T}_{\mathrm{g}}$, e.g., for glasses, to its lowest value $\mathrm{Q}_{\mathrm{L}}$ at high temperatures $\mathrm{T}>>\mathrm{T}_{\mathrm{g}}$, (or more exactly at $\exp \left(\mathrm{T} / \mathrm{T}_{\mathrm{g}}\right)>>1$; see the Discussion chapter), such as for melts. The typical variation of the activation energy of the flow with temperature is illustrated by Figure 1. 


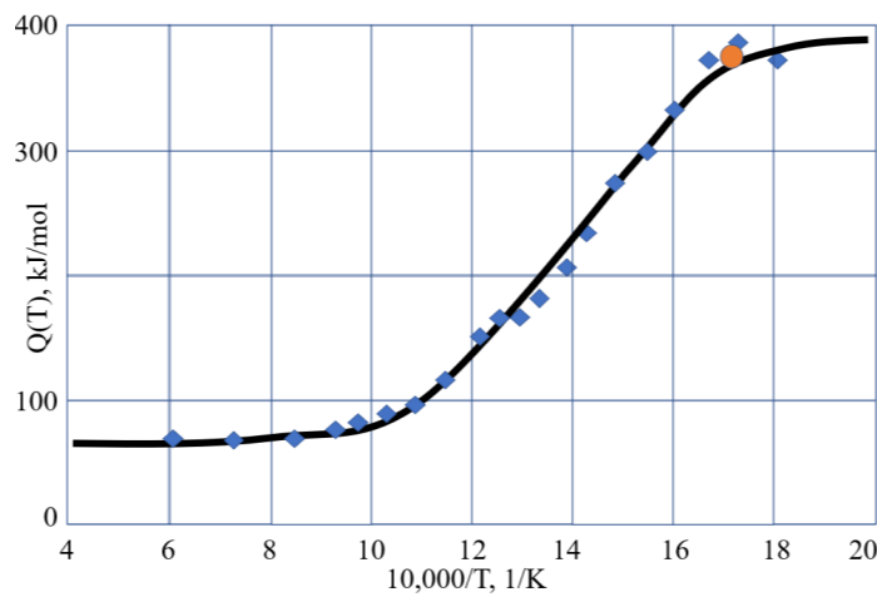

Figure 1. The activation energy of the viscosity $Q(T)$ for vitreous and molten $\mathrm{B}_{2} \mathrm{O}_{3}$. Experimental data are taken from [23]. The orange circle indicates the position of glass transition temperature $\mathrm{T}_{\mathrm{g}}=580 \mathrm{~K}$.

Stickel et al. [2] observed that the highly resolved temperature dependence of the dynamics in salol does not follow a particular function, such as the Vogel-Fulcher-Tammann (VFT) law, over the accessible range of temperatures and that none of the common routes for rationalizing the dynamics, such as Arrhenius, VFT, Souletie scaling, and idealized mode-coupling theory, account for the experimental findings properly. Nevertheless, the VFT behavior was obeyed within the limits of $265 \mathrm{~K} \leq \mathrm{T} \leq$ $320 \mathrm{~K}$, i.e., for temperatures ranging from significantly above the glass transition at $\mathrm{T}_{\mathrm{g}}=220 \mathrm{~K}$ to far above the melting point [2]. Kivelson et al. [3] attempted to assess the applicability of various competing theoretical models by examining the temperature dependence of the viscosity $\eta(T)$ of a wide variety of supercooled liquids, concluding that there is a single dominant species-independent, non-molecular mechanism underlying $\alpha$ relaxation for all supercooled liquids throughout the entire temperature range. It was found that the overall best fits over the entire temperature range above the glass transition temperature are given by the expression $\mathrm{T} \cdot \ln \left[\eta(\mathrm{T}) / \eta_{\infty}\right]=\mathrm{E}_{\infty}+\mathrm{BT} \mathrm{T}^{*}\left[\left(\mathrm{~T}^{*}-\mathrm{T}\right) / \mathrm{T}^{*}\right]^{8 / 3} \Theta\left(\mathrm{T}^{*}\right.$ $-\mathrm{T})$, where $\Theta\left(\mathrm{T}^{*}-\mathrm{T}\right)$ is the Heaviside step function and $\mathrm{T}^{*}$ is usually greater than the melting point temperature. More recently, the Eyring viscosity equation typically used for glass-forming liquids $[12,15]$ was applied to calculate the viscosity, resulting in a modified temperature-dependent Eyring viscosity equation [19]. It was shown that that different regression methods exert a great effect on the final prediction results, although the viscosity of a series of glasses across a wide temperature range was accurately predicted via the optimal regression method [19]. Recent analysis revealed the general structural origin of slow dynamics in glass-forming systems, with strong local structure dynamics correlations with attractive interactions, which affect the liquid structure in a non-perturbative manner [21]. The transition from Arrhenius to non-Arrhenius viscosity behavior between $Q_{H}$ and $Q_{L}$ is observed in glass-forming liquids, in conjunction with anomalies in multiple thermodynamic variables, including the heat capacity, the thermal expansion coefficient, and the isothermal compressibility [22]. Moreover, it was found that the transition occurs very sharply over a temperature interval of about $15 \mathrm{~K}$ for salol, $o$-terphenyl, and $\alpha$-picoline [11]. Doremus proposed the use of the ratio between two activation energies that are well-defined constants of materials, $R_{D}=Q_{H} / Q_{L}$, as a universal and well-defined fragility index of materials, which shows the steepness of the temperature dependence of the viscosity [5]. Short (or fragile) glass melts that have steeper temperature viscosity behavior are, therefore, characterized by high values of $\mathrm{R}_{\mathrm{D}}>2$, whereas long (or strong) glass melts have parameter $\mathrm{R}_{\mathrm{D}}<2$ and demonstrate a relatively weaker change of flow activation energy. One of models that incorporates such viscosity behavior is the Sheffield model, which was shown to give a very exact description of the viscosity-temperature relationships of oxide glasses within a wide temperature range, where the viscosity changes its activation energy from $Q_{H}$ to $Q_{L}$ [8]. It is, however, not known how well this model can be applied for organic materials that are very sensitive to temperature changes, with potential structural rearrangements that may require additional adjustments in using 
the equation. The objective of this paper is to demonstrate that the Sheffield model works for organics and to identify its limits when describing the viscosity dependence, using the same equation with and without parameter adjustment.

\section{Theoretical}

The viscosity quantifies the resistance of material to flow and indicates the ability to dissipate momentum. At the microscopic level, the viscosity arises because of a transfer of momentum between fluid layers moving at different velocities. The tighter the bound layers, the more difficult their motion and the higher the resulting viscosity. As suggested by Mott [24], viscous flow occurs due to flow defects, in which the viscosity is inversely proportional to the concentration of the defects. In 1949, Ronald W. Douglas of the University of Sheffield (UK) devised a model of viscous flow based on the dual roles of oxygen in glasses, which resulted in a two-exponential equation for the temperature dependence of viscosity [25]. Although the equation gave a very good description of viscosity, it has not become popular compared with Vogel-Fulcher-Tammann (VFT), Williams-Landel-Ferry (WLF), Avramov-Milchev, Nemilov, Sanditov, Mauro-Yue-Ellison-Gupta-Allan (MYEGA), and other often used models [1-22]. It is considered that the two-exponential equations such as that obtained by Douglas can exactly describe the viscosity of amorphous materials, as the two-exponential equations with two activation energies can properly account for the asymptotic Arrhenius-type dependences of the viscosity on temperature, having different activation energies at low and high temperatures (compared with $\mathrm{T}_{\mathrm{g}}$ ) -low $\mathrm{Q}_{\mathrm{L}}$ at high and high $\mathrm{Q}_{\mathrm{H}}$ at low temperatures [1]. It should, however, be noted that at very high temperatures, there are deviations from Arrhenius behavior due to critical behavior [26]. The two-exponential equation of viscosity was derived in the 2000s at the University of Sheffield using the notion of defects that assist (facilitate) flow in amorphous materials-configurons, i.e., broken chemical bonds $[27,28]$ :

$$
\eta(T)=A_{1} \cdot T \cdot\left[1+A_{2} \cdot \exp \left(H_{m} / R T\right)\right] \cdot\left[1+C \cdot \exp \left(H_{d} / R T\right)\right]
$$

Here, $\mathrm{A}_{1}=\mathrm{k} / 6 \pi \mathrm{rD}_{0} ; \mathrm{k}$ is Boltzmann constant; $\mathrm{r}$ is the configuron radius; $\mathrm{T}$ is temperature; $A_{2}=\exp \left(-S_{m} / R\right) ; R=8.314 \mathrm{~J} / \mathrm{mol} \cdot \mathrm{K}$ is the absolute gas constant; $\mathrm{C}=\exp \left(-\mathrm{S}_{\mathrm{d}} / \mathrm{R}\right) ; \mathrm{D}_{0}=f g \lambda^{2} \mathrm{zp}_{0} v_{0} ; \mathrm{H}_{\mathrm{d}}$ and $S_{d}$ are the enthalpy and entropy of the configuron (broken bond) formation, respectively; $\mathrm{H}_{\mathrm{m}}$ and $S_{m}$ are the enthalpy and entropy of the configuron motion, respectively; $f$ is the correlation factor; $\mathrm{g}$ is a geometrical factor $(\sim 1 / 6)$; $\lambda$ is the average jump length; $\mathrm{z}$ is the number of nearest neighbors; $\mathrm{p}_{0}$ is a configuration factor; $v_{0}$ is the configuron vibrational frequency or the frequency with which the configuron attempts to surmount the energy barrier to jump into a neighboring site.

Comprehensive comparisons of viscosity models available for a number of oxide glasses were provided by Starodub et al [16], Sturm [17], and Chen et al. [19]. Starodub et al. [16] demonstrated that the outcomes of modeling can be effectively improved by using machine learning techniques applied to multiparameter tasks. Chen et al. [19] found that the viscosity values simulated by using both high-temperature and low-temperature viscosity data show higher accuracy than those using only high-temperature viscosity data. Although the Sheffield model in Sturm's analysis [17] did not rank the best among known viscosity models, it provides a direct link between the bond's strength and the activation energy of viscosity, which reveals the processes behind the variation of activation energy. In contrast to many other approximations, Equation (1) can be used over a wider temperature range and gives the correct Arrhenius-type asymptotes at high and low temperatures, namely $\eta(T)=A \cdot T \cdot \exp \left(H_{m} / R T\right)$, where $A=A_{1} A_{2}$, and $\eta(T)=A \cdot C \cdot T \cdot \exp \left[\left(H_{m}+H_{d}\right) / R T\right]$, respectively.

The low activation energy of the flow at high temperatures is $Q_{L}=H_{m}$, whereas the high activation energy is $\mathrm{Q}_{\mathrm{H}}=\left(\mathrm{H}_{\mathrm{m}}+\mathrm{H}_{\mathrm{d}}\right)$ at low temperatures. The physical meaning of these equalities is straightforward - at high temperatures, the defects of the flow in the form of broken bonds (configurons) are so abundant that the only barrier to overcome is due to configuron motion i.e. a sort of friction between imaginary layers of liquid. In contrast, at low temperatures it is necessary to create flow 
defects; that is, to break the bonds. Therefore, the activation energy is higher because of the enthalpy of the formation of configurons $\left(\mathrm{H}_{\mathrm{d}}\right)$.

For the activation energies of the viscosity, Volf gives the following data: $\mathrm{Q}_{\mathrm{L}}=80-300 \mathrm{~kJ} / \mathrm{mol}$ for the low viscosity range, e.g., when $\log (\mathrm{\eta} /$ Poise $)<3 ; \mathrm{Q}_{\mathrm{H}}=400-800 \mathrm{~kJ} / \mathrm{mol}$ for the high viscosity range, e.g., when $\log (\eta /$ Poise $)>10$ [1]. Although within the intermediate ranges of temperatures it gives practically the same description of viscosity as other commonly used models, the Sheffield equation has two asymptotic Arrhenius-type limits at high and low temperatures, with low activation energy at high temperatures and high activation energy at low temperatures. The low activation energy equals the enthalpy of motion of configurons $\mathrm{H}_{\mathrm{m}}$, whereas the high activation energy equals the sum of the enthalpies of motion with the enthalpy of formation of configurons $\mathrm{H}_{\mathrm{m}}+\mathrm{H}_{\mathrm{d}}$. Moreover, the Sheffield equation shows that all materials have a minimal achievable viscosity, which was recently confirmed by quantum mechanical analysis of Tracheko and Brazhkin [29].

Equation (1) has been used with many materials and has been proven to be valid universally at both low (for glasses) and high (for liquids) temperatures [8,30-32]. It is also worth noting that the first exponential term of Equation (1) is extremely high in terms of compared unity, which means that the term $\left[1+\mathrm{A}_{2} \cdot \exp \left(\mathrm{H}_{\mathrm{m}} / \mathrm{RT}\right)\right]$ in Equation (1) can be substituted for simply $\mathrm{A}_{2} \cdot \exp \left(\mathrm{H}_{\mathrm{m}} / \mathrm{RT}\right)$. This reduces Equation (1) to an equation with only 4 fitting parameters $\left(A=A_{1} \cdot A_{2}, H_{m}, C\right.$, and $\left.H_{d}\right)$ instead of 5 fitting parameters:

$$
\eta(T)=A \cdot T \cdot \exp \left(H_{m} / R T\right) \cdot\left[1+C \cdot \exp \left(H_{d} / R T\right)\right]
$$

There is no need to use 5 fitting parameters $\left(\mathrm{A}_{1}, \mathrm{~A}_{2}, \mathrm{H}_{\mathrm{m}}, \mathrm{C}\right.$, and $\left.\mathrm{H}_{\mathrm{d}}\right)$ in calculations, as Equation (2) with only 4 fitting parameters suffices for an exact description of viscosity. We should, however, account for the fact that approximation of the temperature-independent enthalpy and entropy of the formation and migration of configurons $\left(\mathrm{H}_{d}\right.$ and $\mathrm{S}_{\mathrm{d}}, \mathrm{H}_{\mathrm{m}}$, and $\left.\mathrm{S}_{\mathrm{m}}\right)$ is not always adequate over all temperature ranges and cannot be extended for indefinite temperatures. Those energies and entropies should depend on the material density at first, so that thermal expansion must have an effect on them (see [6,20]). Physical transformations in the materials (e.g., structural changes or boiling) can also significantly change these parameters. Therefore, we cannot always expect the same coefficients A and $\mathrm{H}_{\mathrm{m}}$ at very high temperatures as those that are based on processing data from temperatures lower than the melting temperatures of materials. In this high temperature range, we should again find coefficients $\mathrm{A}$ and $\mathrm{H}_{\mathrm{m}}$ and compare them with lower temperature data for consistency.

The glass transition temperature in the configuron percolation theory of glass transition is given by:

$$
\mathrm{T}_{\mathrm{g}}=\mathrm{H}_{\mathrm{d}} /\left\{\mathrm{S}_{\mathrm{d}}+\mathrm{R} \cdot \ln \left[\left(1-\phi_{\mathrm{c}}\right) / \phi_{\mathrm{c}}\right]\right\}
$$

where $\phi_{\mathrm{c}}$ is the percolation threshold, which determines when the first time a percolation cluster made of broken bonds-configurons-is formed [28]. Therefore, we can substitute the term $C=\exp \left(-S_{d} / R\right)$ related to the entropy of the formation of configurons $S_{d}$ in Equation (2) by $C=[(1-$ $\left.\left.\phi_{\mathrm{c}}\right) / \phi_{\mathrm{c}}\right] \cdot \exp \left(-\mathrm{H}_{\mathrm{d}} / \mathrm{RT}_{\mathrm{g}}\right)$, which leads to:

$$
\eta(T)=A \cdot T \cdot \exp \left(H_{m} / R T\right) \cdot\left\{1+\left[\left(1-\phi_{c}\right) / \phi_{c}\right] \cdot \exp \left[\left(H_{d} / R\right)\left(1 / T-1 / T_{g}\right)\right]\right\}
$$

Equation (4) can be further exploited, as it explicitly relates the viscosity to the glass transition temperature. The $T_{g}$ in (4) is the temperature, which is found via differential scanning calorimetry measurements, however here it is not presumed to result in $\log \left[\eta\left(T_{g}\right)\right]=12$, as typically is the case in other models (e.g., [18]).

At temperatures below the $T_{g}$, the Sheffield equation simplifies to the following equation:

$$
\eta(T)=A \cdot\left[\left(1-\phi_{c}\right) / \phi_{c}\right] \cdot \exp \left[\left(-H_{d} / R T_{g}\right] \cdot T \cdot \exp \left[\left(H_{m}+H_{d}\right) / R T\right)\right]
$$


Hence, we can find from the low temperature range the high activation energy of the flow $\mathrm{Q}_{\mathrm{H}}=\left(\mathrm{H}_{\mathrm{m}}+\mathrm{H}_{\mathrm{d}}\right)$ and the percolation threshold $\phi_{\mathrm{c}}$, which for strong liquids is $\approx 0.15$ [8]. At temperatures far above the $T_{g}$ when $\exp \left(T / T_{g}\right)>1$, the Sheffield equation simplifies into the following equation:

$$
\eta(T)=A \cdot T \cdot \exp \left(H_{m} / R T\right)
$$

Hence, from the high temperature range, we can find both the constant $\mathrm{A}$ and the low activation energy of the flow $Q_{L}=H_{m}$. In this range, the Sheffield equation reveals a relatively shallow minimum viscosity. This can be readily found using the Equation (6) as follows:

$$
\eta_{\min }=\mathrm{e} \cdot \mathrm{A} \cdot \mathrm{H}_{\mathrm{m}} / \mathrm{R}
$$

where $\mathrm{e}=2.71828$ is the Euler number. The minimum viscosity occurs at the temperature found from the below equation:

$$
\mathrm{T}_{\mathrm{vm}}=\mathrm{H}_{\mathrm{m}} / \mathrm{R}
$$

The Sheffield model of viscosity is universal for all kinds of amorphous materials and enables a good description of viscous flow in both glasses and melts. This is demonstrated in the current paper for two glass-forming organic materials_-salol and cresol_-also aiming to identify the limits of the model while describing the viscosity dependence with the same equation with or without parameter adjustment. Other materials with known data on temperature relationships of viscosity can also be analyzed, however this is out of the scope of this publication.

\section{Viscosity of Salol}

Salol, i.e., phenyl salicylate $\mathrm{C}_{13} \mathrm{H}_{10} \mathrm{O}_{3}$, is used in the manufacture of some polymers, lacquers, adhesives, waxes, and polishes. Salol is also important for glass science as a model material (e.g., see the detailed analysis of salol dynamics in [2]). We have analyzed data on the temperature dependence of the viscosity of salol and $\alpha$-phenyl-o-cresol taken from [33]. The coefficients of viscosity in Equations (1) and (2) were found using the best fitting procedure, utilizing both analytic [30] and genetic algorithm [8] approaches. Table 1 lists these coefficients, which are directly related to the thermodynamic parameters of configurons, e.g., enthalpies and entropies of formation and motion [8,27].

Table 1. Parameters of the Sheffield equation of viscosity ${ }^{1}$ for salol.

\begin{tabular}{cccccc}
\hline $\mathbf{A}_{\mathbf{1}}, \mathbf{P a} \cdot \mathbf{s} / \mathbf{K}$ & $\mathbf{A}_{\mathbf{2}}$ & $\mathbf{A}=\mathbf{A}_{\mathbf{1}} \cdot \mathbf{A}_{\mathbf{2}}, \mathbf{P a} \cdot \mathbf{s} / \mathbf{K}$ & $\mathbf{H}_{\mathbf{m}}, \mathbf{k J} / \mathbf{m o l}$ & $\mathbf{C}$ & $\mathbf{H}_{\mathbf{d}}, \mathbf{k J} / \mathbf{m o l}$ \\
\hline $1.78 \cdot 10^{-24}$ & 0.0114 & $2.03 \cdot 10^{-26}$ & 118.41 & $2.57 \cdot 10^{-30}$ & 145.17 \\
\hline \multicolumn{6}{c}{$\mathrm{Pa} \cdot \mathrm{s}=10 \mathrm{P}$ (Poise, the non-system unit of viscosity). }
\end{tabular}

Figure 2 shows the viscosity of salol within the temperature range of 200-300 K in a logarithmic scale. The solid curve is calculated by the two Sheffield equations (Equations (1) and (2)) using the parameters from Table 1.

Comparison of the experimental data with those calculated using the Sheffield equation reveals a very good description of the viscosity, with the root mean squared error (RMSE) characterizing the fit (RMSE $=0.085)$. We note that the glass transition temperature of salol is $\mathrm{T}_{\mathrm{g}}=220 \mathrm{~K}$, as found from the heat capacity dependence on temperature [33], and we observe that the viscosity of salol at the glass transition temperature $\log \left[\eta\left(T_{\mathrm{g}}\right)\right]=9.64$ is significantly (hundreds of times) below the generic and arbitrary definition of the glass transition as taking place at $\log \left[\eta\left(\mathrm{T}_{\mathrm{g}}\right)\right]=12[34-36]$. There is a clear change of the activation energy of the viscous flow from its high value $Q_{H}=263.6 \mathrm{~kJ} / \mathrm{mol}$ at temperatures below $\sim 220 \mathrm{~K}$ to its low value $\mathrm{Q}_{\mathrm{L}}=118.4 \mathrm{~kJ} / \mathrm{mol}$ at temperatures above $\sim 260 \mathrm{~K}$. The temperature $\mathrm{T}_{2}=260 \mathrm{~K}$, above which the viscosity of salol is described by the Arrhenius-type equation (6), is revealed by the inset of Figure 2, which shows that the term $\left[1+C \cdot \exp \left(\mathrm{H}_{\mathrm{d}} / \mathrm{RT}\right)\right]$ is practically equal to 1 above $260 \mathrm{~K}$, and only below $\mathrm{T}_{2}$ shall it be accounted for as deviating from the 
unity. Figure 2 also shows that above temperature $\mathrm{T}_{2}$ the Arrhenius behavior of the viscosity is not much different to $T_{g}$. This means that all temperatures above $T_{g}$ can be used in finding the fitting coefficients of the Sheffield equation by applying the analytical procedure described in [30].

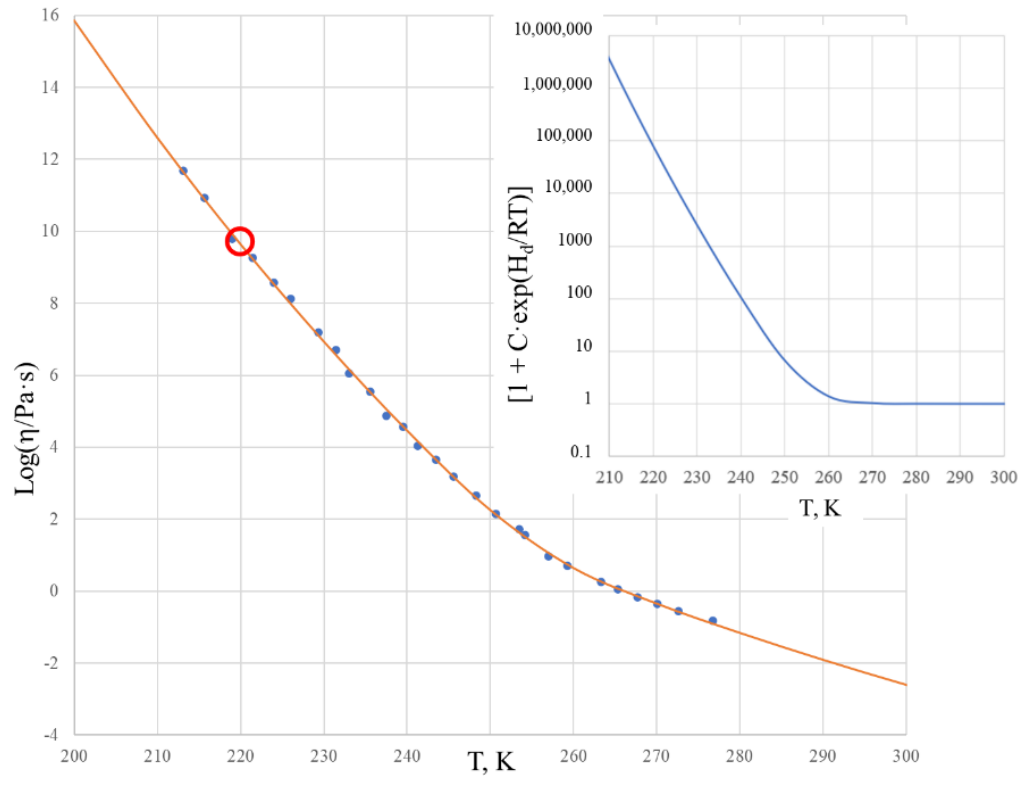

Figure 2. The viscosity of vitreous and molten salol. The theoretical curve was calculated using the two Sheffield equations (Equations (1) and (2)). Experimental data were taken from [33], with the red circle indicating the $\mathrm{T}_{\mathrm{g}}=220 \mathrm{~K}$ [33]. The inset shows the temperature dependence of factor $\left[1+\mathrm{C} \cdot \exp \left(\mathrm{H}_{\mathrm{d}} / \mathrm{RT}\right)\right]$ in Equations (1) and (2).

It is also worth noting that the first exponential term of the Sheffield equation (Equation (1)) is extremely high compared with unity, e.g., it changes from $9.6 \cdot 10^{28}$ at $\mathrm{T}=200 \mathrm{~K}$ to $2.7 \cdot 10^{10}$ at $\mathrm{T}=500 \mathrm{~K}$. This confirms that Equation (2) can be used instead of Equation (1) without any loss of accuracy. There is no need to use 5 fitting parameters in the calculations, as the Equation (2) with only 4 fitting parameters suffices for an exact description of the viscosity. Finally, we can calculate the Doremus fragility ratio $R_{D}=Q_{H} / Q_{L}$ using the data from Table 1 as follows: $R_{D}=1+H_{d} / H_{m}$. One can see that salol is a typical fragile liquid with a Doremus fragility ratio of $R_{D}=2.2$, which is not much above 2 .

The viscosity of salol was further analyzed at high temperatures by Cukierman, Lane, and Uhlmann [37]. These data revealed that the activation energy of the flow, e.g., $\mathrm{H}_{\mathrm{m}}$ in Equation (6), is much lower than that obtained above (Table 1). Using high-temperature viscosity data for salol from [37], an attempt was made to use the Sheffield equation throughout all temperature ranges using a modified set of fitting parameters, which is shown in Figure 3.

Deviations of the theoretical curve in the experiment within the temperature range of 260-280 K are unacceptably large. We recall that the behavior in this range is well described by Equation (2) when using data from [33] only (see Figure 2). This reveals that parameters $A$ and $H_{m}$ in the high temperature range differ significantly from those obtained using data closer to $\mathrm{T}_{\mathrm{g}}$, as in given in Table 1. This demonstrates that the Sheffield equation, although describing the trends for the temperature dependence of the viscosity well, fails to exactly describe these trends based on the same parameters throughout all temperature ranges. Deviations from the experiment, as seen in Figure 3, are unacceptable in the range where the viscosity is already described by the Arrhenius-type relationship (6), although the parameters of this relationship can change due to thermal expansion, structural rearrangements, boiling, etc. The enthalpy of the motion of configurons $\mathrm{H}_{\mathrm{m}}$ dropped from $\mathrm{H}_{\mathrm{mL}}=118.41 \mathrm{~kJ} / \mathrm{mol}$ at temperatures below $280 \mathrm{~K}$ (see Table 1 ) to $\mathrm{H}_{\mathrm{mH}}=21.3 \mathrm{~kJ} / \mathrm{mol}$ above $320 \mathrm{~K}$, which most probably was due to the structural complexity of salol molecules, as shown by the inset in Figure 3. 


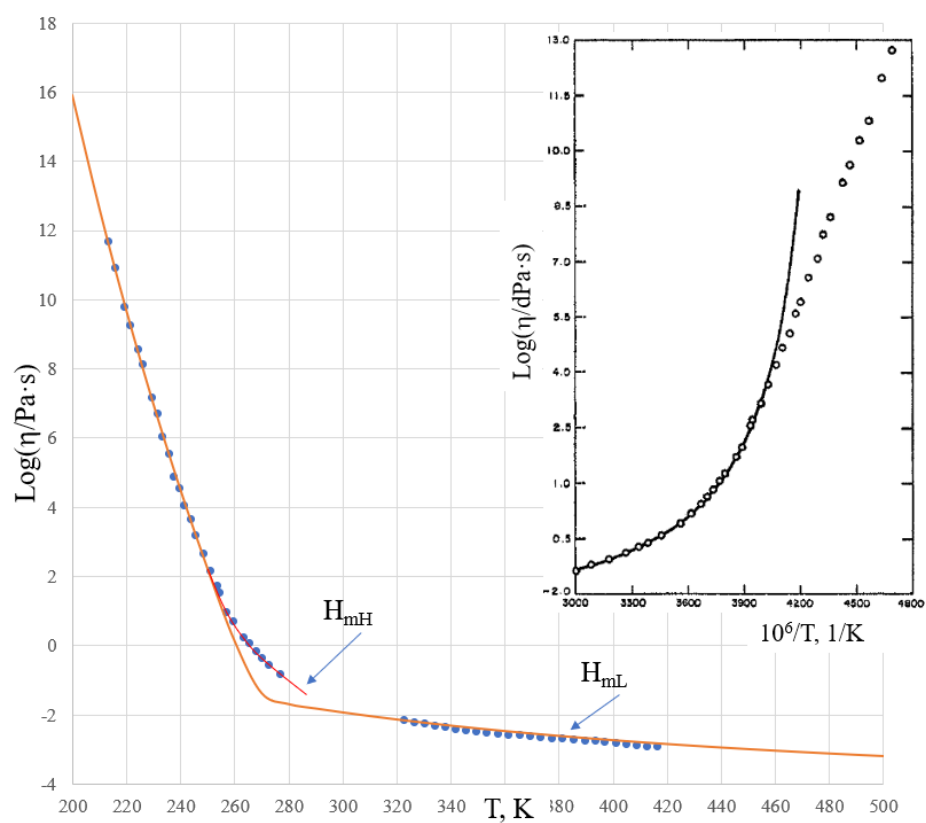

Figure 3. The viscosity of vitreous and molten salol over a wide temperature range. The theoretical curve was calculated using Equation (2), with the same parameters $A, H_{m}, C$, and $H_{d}$ used at all temperatures. Experimental data were taken from [33] for lower temperatures $(\mathrm{T}<280 \mathrm{~K})$ and from [37] for the high temperature range $(\mathrm{T}>320 \mathrm{~K})$. The inset shows the viscosity curve by VFT approximation [33].

\section{Viscosity of Cresol}

Cresol, i.e., $\alpha$-phenyl-o-cresol, belongs to the group of organic compounds of cresols that are precursors to many compound materials, including plastics, pesticides, pharmaceuticals, and dyes. We have analyzed data on the temperature dependence of the viscosity of $\alpha$-phenyl-o-cresol taken from [24]. The viscosity coefficients in Equations (1) and (2) were found using the best fitting procedure, utilizing both analytic [30] and genetic algorithm [8] approaches (Table 2).

Table 2. Parameters of the Sheffield equation of viscosity for $\alpha$-phenyl-o-cresol.

\begin{tabular}{cccccc}
\hline $\mathbf{A}_{\mathbf{1}}, \mathbf{P a} \cdot \mathbf{s} / \mathbf{K}$ & $\mathbf{A}_{\mathbf{2}}$ & $\mathbf{A}=\mathbf{A}_{\mathbf{1}} \cdot \mathbf{A}_{\mathbf{2}}, \mathbf{P a} \cdot \mathbf{s} / \mathbf{K}$ & $\mathbf{H}_{\mathbf{m}}, \mathbf{k J} / \mathbf{m o l}$ & $\mathbf{C}$ & $\mathbf{H}_{\mathbf{d}}, \mathbf{k J} / \mathbf{m o l}$ \\
\hline $2.2 \cdot 10^{-22}$ & 0.1341 & $2.95 \cdot 10^{-23}$ & 103.22 & $3.85 \cdot 10^{-37}$ & 172.15 \\
\hline
\end{tabular}

Figure 4 shows the viscosity of $\alpha$-phenyl-o-cresol within the temperature range of $200-300 \mathrm{~K}$ in a logarithmic scale, calculated using the two Sheffield equations (Equations (1) and (2)) with experimental data taken from [33].

Comparison of the experimental data with the calculated data reveals the very good description of the viscosity using the Sheffield equation, with RMSE $=0.11$. With the glass transition temperature $T_{g}=220 \mathrm{~K}$ [33], the $\alpha$-phenyl-o-cresol has a logarithm of viscosity at $T_{g}$ as high as 8.78, which means that the viscosity is more than 1500 (1659) times below the generically considered value $\log \left[\eta\left(T_{g}\right)\right]=12$ [34-36]. The viscosity shows a significant change of activation energy from its high value $Q_{H}=275.37 \mathrm{~kJ} / \mathrm{mol}$ at temperatures below $\sim 220 \mathrm{~K}$ to its low value $Q_{\mathrm{L}}=103.22 \mathrm{~kJ} / \mathrm{mol}$ at temperatures above $\mathrm{T}_{2}=240 \mathrm{~K}$, where the viscosity can be described by the Arrhenius-type equation (Equation (6)). The inset of Figure 4 shows that the term $\left[1+\mathrm{C} \cdot \exp \left(\mathrm{H}_{\mathrm{d}} / \mathrm{RT}\right)\right]$ is practically equal to 1 above $240 \mathrm{~K}$, and only below this shall it be considered to deviate from the unit. Similarly to salol, the first exponential term of the Sheffield equation for $\alpha$-phenyl-o-cresol is extremely high, i.e., it changes from $1.22 \cdot 10^{26}$ at $\mathrm{T}=200 \mathrm{~K}$ to $8.14 \cdot 10^{9}$ at $\mathrm{T}=500 \mathrm{~K}$, meaning that the term $\left[1+\mathrm{A}_{2} \cdot \exp \left(\mathrm{H}_{\mathrm{m}} / \mathrm{RT}\right)\right]$ in Equation (1) can be substituted for $A_{2} \cdot \exp \left(\mathrm{H}_{\mathrm{m}} / \mathrm{RT}\right)$, which reduces the first Sheffield equation 
(Equation (1)) to its simplified form (Equation (2)) with only 4 fitting parameters, e.g., A, $H_{m}, C$, and $H_{d}$. The Doremus fragility ratio is $R_{D}=2.67$, demonstrating that $\alpha$-phenyl-o-cresol is a more fragile liquid compared with salol.

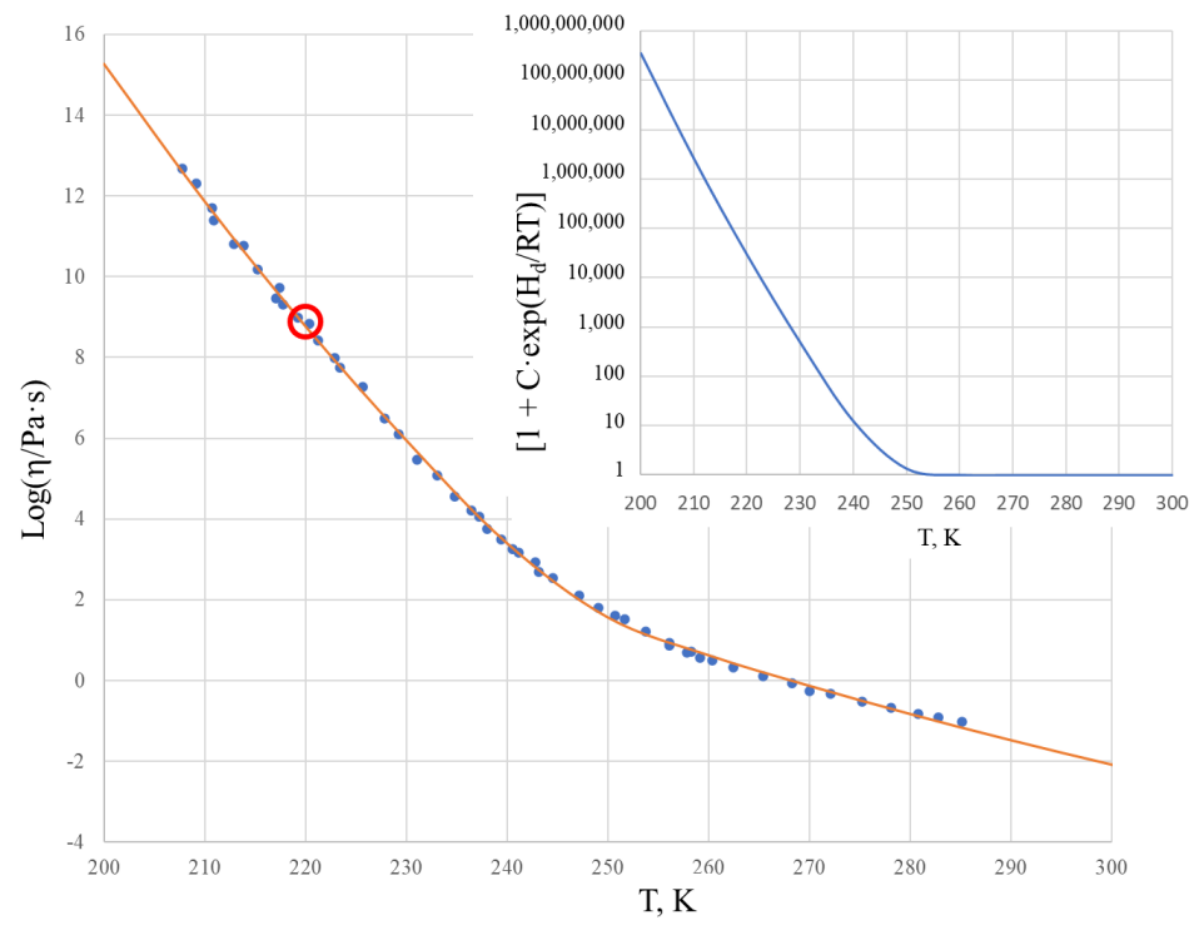

Figure 4. The viscosity of vitreous and molten $\alpha$-phenyl-o-cresol using the two Sheffield equations (Equations (1) and (2)). Experimental data were taken from [33], with the red circle indicating $\mathrm{T}_{\mathrm{g}}=220 \mathrm{~K}$ [33]. The inset shows the temperature dependence of factor $\left[1+\mathrm{C} \cdot \exp \left(\mathrm{H}_{\mathrm{d}} / \mathrm{RT}\right)\right]$ in Equations (1) and (2).

We note that similarly to salol, attempts have failed to model the viscosity-temperature relationships of cresol when accounting for the high temperature range data from [38] and using the same parameters $\mathrm{A}, \mathrm{H}_{\mathrm{m}}, \mathrm{C}$, and $\mathrm{H}_{\mathrm{d}}$ in Equation (2) at all temperatures. The enthalpy of motion of the configurons of $\alpha$-phenyl-o-cresol $\mathrm{H}_{\mathrm{m}}$ dropped from $\mathrm{H}_{\mathrm{mL}}=103.22 \mathrm{~kJ} / \mathrm{mol}$ for temperatures below $290 \mathrm{~K}$ (Table 2) to $\mathrm{H}_{\mathrm{mL}}=25.62 \mathrm{~kJ} / \mathrm{mol}$ above $320 \mathrm{~K}$. This reveals that similarly to salol, the Sheffield equation cannot be used for $\alpha$-phenyl-o-cresol with the same thermodynamic constants $H_{d}, S_{d}, H_{m}$, and $S_{m}$ at all temperatures.

\section{Discussion}

The temperature dependence of viscosity of amorphous materials $\eta(T)$ is a continuous function of the temperature T, which has two exact Arrhenius-type asymptotes at high and low temperatures compared with $T_{g}$. At intermediate temperatures, the activation energy of the viscous flow $Q(T)$ is a function of the temperature, e.g., it can be used in an Arrhenius-type equation $\eta(T)=A \cdot T \cdot \exp (Q / R T)$, where it formally depends on the temperature. There are many effective models of viscosity to account for this [1-22,39-43], with two of the most frequently used models being the Williams-Landel-Ferry (WLF) equation for polymers and the Vogel-Fulcher-Tammann (VFT) equation for inorganic materials. The WLF equation typically used for polymers is [39]:

$$
\eta(T)=\eta_{0} \cdot \exp \left[-C_{1} \cdot\left(T-T_{0}\right) /\left(C_{2}+T-T_{0}\right)\right]
$$


where $\eta_{0}$ is a constant and $T_{0}$ is taken as $T_{g}$, whereas $C_{1}$ and $C_{2}$ are universal constants for most polymeric materials. The VFT equation of viscosity describes viscosity data at intermediate temperatures over many orders of magnitude with quite high accuracy [7]:

$$
\eta(T)=\eta_{0} \cdot \exp \left[B /\left(T-T_{0}\right)\right]
$$

where $\eta_{0}, B$, and $T_{0}$ (Vogel temperature) are material specific constants. Although both (9) and (10) give very good descriptions of viscosity within an intermediate range of temperatures, neither correctly describe the asymptotic behavior of viscosity, which is naturally of the Arrhenius-type. As noted in [33], the VFT equation greatly overestimates the viscosity for both salol (see the inset of Figure 3) and cresol.

The above results for the temperature behavior of the viscosity of salol and cresol have shown that the four-parameter equation (Equation (2)) can be used with practically the same results as the Sheffield equation (Equation (1)), facilitating the fitting procedures needed to find parameters $A, H_{m}$, $C$, and $H_{d}$ of this equation. We note that Equation (2) is the one that Volf claimed to be the best at mathematically describing the viscosities of condensed materials [1], and it is the same type of equation that Douglass derived for silicate systems in 1949 [25]. Numerical data show that just below $T_{g}$, the activation energy of the flow for both salol and cresol becomes constant and high, e.g., $Q_{H}$. When exceeding the $\mathrm{T}_{\mathrm{g}}$ by about 20 to $40 \mathrm{~K}$, the activation energy of the flow for both salol and cresol rapidly becomes almost constant and low, e.g., $Q_{L}$. The transformation range where the activation energy of flow $\mathrm{Q}(\mathrm{T})$ is temperature-dependent and changes from $\mathrm{Q}_{\mathrm{H}}$ to $\mathrm{Q}_{\mathrm{L}}$ is, thus, narrow in the temperature scale, although the changes in the viscosity are drastic and cover many orders of magnitude. We also observe that the actual changes of $\mathrm{Q}(\mathrm{T})$ occur only above $\mathrm{T}_{\mathrm{g}}$ in the undercooled liquid, while in the glassy state the $\mathrm{Q}(\mathrm{T})$ is almost unchanged and equal $\mathrm{Q}_{\mathrm{H}}$. As seen from Figure 1, this is also the case for $\mathrm{B}_{2} \mathrm{O}_{3}$, which is also a fragile liquid, with $\mathrm{R}_{\mathrm{D}}=3.28$ [8,30]. Analysis of the activation energy for the viscosity of silica, which is a strong (long) liquid, shows that $Q(T)$ changes over a wider range within the glassy state [43], although this range is narrow compared to $\mathrm{T}_{g}$. Accounting for this, we can conclude that the Arrhenius-type behavior of the viscosity with low activation energy $\mathrm{Q}_{\mathrm{L}}$ occurs when $\exp \left(\mathrm{T} / \mathrm{T}_{\mathrm{g}}\right)>1$ rather than requesting $\mathrm{T} / \mathrm{T}_{\mathrm{g}}>>1$, which is a very strong requirement when processing experimental data [30]. This result simplifies the utilization of the analytical procedures used to determine parameters $\mathrm{A}, \mathrm{H}_{\mathrm{m}}, \mathrm{C}$, and $\mathrm{H}_{\mathrm{d}}$ of the second Sheffield equation (Equation (2)). Both Equations (1) and (2) (as seen from Figures 2 and 4) resulted in very good descriptions of the viscosity within the transformation range where the activation energy varies, similar to the results given by the well-known WLF equation (Equation (9)) and VFT equation (Equation (10)). Compared with those equations, however, we can extend the temperature ranges for both low and high temperatures. This extension is not indefinite in practice, as we found above for both salol and cresol. In the high temperature range above $320 \mathrm{~K}$, the enthalpy of motion for configurons for both salol and $\alpha$-phenyl-o-cresol decreases significantly, which could be due to the relative complex molecular structures of these organic materials. Indeed, due to thermal expansion, more free volume becomes available for molecules to move [20,27]. The enthalpy of motion of configurons is analogous to the elastic strain energy in glass, with $\mathrm{H}_{\mathrm{m}}$ estimated as $\mathrm{H}_{\mathrm{m}}=\pi \mu \cdot\left(\mathrm{r}-\mathrm{r}_{\mathrm{dr}}\right)^{2} \cdot \lambda$, where $\mu$ is the shear modulus of the glass, $\mathrm{r}$ is the radius of configuron and $\lambda$ is average jump length as in Equation (1), and $r_{d r}$ is the radius of the network doorway [27]. At higher temperatures, $r_{d r}$ increases due to thermal expansion, thus diminishing $\mathrm{H}_{\mathrm{m}}$, which is in line with Frenkel's original idea that the thermal fluctuations increase the cage radius and enable the atom to escape the cage. It is notable that for simpler inorganic (oxide) systems such as diopside, using the same thermodynamic constants $H_{d}, S_{d}, H_{m}$, and $S_{m}$ the Sheffield equation gives an exact description of the viscosity-temperature relationships at all temperatures, including in the high temperature range (see Figure 1 in [8]). Therefore, the modification of $\mathrm{H}_{m}$ at high temperatures is material-specific and cannot be generic for all materials.

Recently, Trachenko and Brazhkin found that all materials have a certain minimum achievable viscosity [29]. It is obvious that the Sheffield equation also exhibits a low minimum viscosity at very 
high temperatures, after which the viscosity increases with the increase of temperature. Based on data in the high temperature range from [37] from Equations (7) and (8), we can find both the minimum viscosities and temperatures at which these are attained (Table 3 ).

Table 3. Minimal theoretical viscosities.

\begin{tabular}{ccc}
\hline Material & $\mathbf{T}_{\mathbf{v m}}, \mathbf{K}$ & $\eta_{\min }, \mathbf{P a} \cdot \mathbf{s}$ \\
\hline Salol & 2562 & $5.35 \cdot 10^{-5}$ \\
$\alpha$-phenyl-o-cresol & 3924 & $4.75 \cdot 10^{-5}$ \\
\hline
\end{tabular}

However, as pointed out by Louzguine-Luzgin et al. [26], the temperature dependence of the viscosity has physical limitations on the high temperature part, where in practice it is valid up to the boiling point at pressure ranges from the triple point to the critical pressure and nearly up to the critical temperature at high pressure. The temperatures where minima can theoretically be achieved by salol $(2562 \mathrm{~K})$ and $\alpha$-phenyl-o-cresol (3924 K) are extremely high, which was not the case in experiment. Therefore, extension of the viscosity plots to such extremely high temperatures for these organic materials is not possible. One can expect decomposition of these molecules much before these extremely high temperatures, so minima in both materials should appear at a much lower temperature than predicted in Table 3.

We have observed that the main variations of the activation energy of the viscous flow in salol and $\alpha$-phenyl-o-cresol occur above $\mathrm{T}_{\mathrm{g}}$. The viscosities at the glass transition temperatures of both salol $\left(\log \left[\eta\left(T_{g}\right)\right]=9.64\right)$ and $\alpha$-phenyl-o-cresol $\left(\log \left[\eta\left(T_{g}\right)\right]=8.78\right)$ are several orders of magnitude below the generically accepted value of the logarithm of viscosity, which is as high as 12 at the conventional glass transition temperature [34-36]. Moreover, the former arbitrary definition of the glass transition temperature is often related to other viscosities; for example, Laughlin and Uhlmann used the temperature corresponding to a viscosity of $10^{15} \mathrm{P}$ (e.g., $10^{14} \mathrm{~Pa} \cdot \mathrm{s}$ ) as $\mathrm{T}_{\mathrm{g}}$ [33]. Mazurin noted that the widespread idea that the glass transition temperatures of all glasses corresponds to the temperature at which the glass viscosity is $10^{12} \mathrm{~Pa} \cdot \mathrm{s}$ is not justified, although most of the glasses do obey this rule [44]. These data, along with data on the viscosities of other materials at different $\mathrm{T}_{\mathrm{g}}$ values [45], question the concept of the universality of defining $T_{g}$ values from the equation $\log \left[\eta\left(\mathrm{T}_{\mathrm{g}}\right)\right]=12$.

The transition of glass is most often considered to be a gradual change from ergodic to non-ergodic states without structural changes, where it is assumed that the glassy state of the amorphous materials is inherently non-ergodic [46]. The observed glass transition viscosity levels below $10^{12} \mathrm{~Pa} \cdot \mathrm{s}$ for some materials, along with evident changes in the heat capacity and thermal expansion coefficient at $T_{g}$, indicate that glass transition is a phase transformation $[28,45,47,48]$. This transformation is similar to a second-order phase transition in the Ehrenfest sense, with continuity of the volume and entropy and discontinuity of their derivatives, which are used in practice to identify $\mathrm{T}_{\mathrm{g}}$. The glass transition is accompanied by significant structural changes, which are revealed via X-ray diffraction [49], high-precision measurements of third- and fifth-order non-linear dielectric susceptibilities that strongly support theories based on the thermodynamic amorphous order, which is fractal in its dimensions [50], as well as direct visualization of macroscopic percolating clusters formed by molecules at the glass transition [51]. The glass transition should be considered as an example of critical phenomena generically termed topological phase transitions, which are amenable to the scaling approach and characterized by diverging length and time at the transition [28,52]. Angell's concept of configurons in covalently bonded systems [53] and Egami's ideas of local connectivity in amorphous metals [54] allows the glass-liquid transition to be treated as a percolation-type phase transformation of the system of chemical bonds. The structural difference between glasses and liquids near $\mathrm{T}_{\mathrm{g}}$ becomes obvious in terms of the Hausdorff dimensionality D of the system of configurons, so that in glasses the set of configurons has $\mathrm{D}=0$ because broken bonds are point-type defects, whereas in liquids the configurons form extended structures-macroscopic percolation clusters with the fractal dimension $\mathrm{D}=2.5$ [55]. As for the entropy, energy. and enthalpy of glasses, as emphasized by Nemilov $[39,40,56]$, these are functionals 
in the thermodynamics of the vitreous state, with additional internal (structural, ordering) parameters that are used along with temperature and pressure, which determine the state of the system in Gibbs thermodynamics. The processing of experimental viscosity data is important in order to identify not only the rheological properties of materials, but also other material parameters. The Sheffield equation of viscosity provides data on chemical bond parameters, including both enthalpies and entropies. Recently developed artificial intelligence and machine learning techniques (see $[16,19,57]$ ) can effectively give detailed information on the bonding system of materials, thereby contributing to efforts to improve the properties and functionalities of novel glasses.

\section{Conclusions}

Utilization of the Sheffield equation of viscosity for glass-forming organic materials is successfully demonstrated for two cases-salol and $\alpha$-phenyl-o-cresol. In both cases, it is numerically confirmed that the simplified variant of the Sheffield equation $\eta(T)=A \cdot T \cdot \exp \left(H_{m} / R T\right) \cdot\left[1+C \cdot \exp \left(H_{d} / R T\right)\right]$, which has 4 fitting parameters, provides data in good agreement with the experiment. It was revealed that above the glass transition temperature, when $\exp \left(\mathrm{T} / \mathrm{T}_{\mathrm{g}}\right)>1$, and just below the $\mathrm{T}_{\mathrm{g}}$ the viscosity can be described using the asymptotic versions of the Sheffield equation, which are Arrhenius-type and have low and high flow activation energies, e.g., $\mathrm{Q}_{\mathrm{L}}=\mathrm{H}_{\mathrm{m}}$ and $\mathrm{Q}_{\mathrm{H}}=\left(\mathrm{H}_{\mathrm{m}}+\mathrm{H}_{\mathrm{d}}\right)$, respectively. Calculations show that the main changes of the flow activation energy in both salol and $\alpha$-phenyl-o-cresol occur above $\mathrm{T}_{\mathrm{g}}$, with variations occurring in a relatively narrow temperature range of about 20 to 40 degrees. Analysis of the viscosity behavior revealed that the parameters of the Sheffield equation are not universal and are modified in the high temperature range both for salol and $\alpha$-phenyl-o-cresol, where the enthalpy of configuron migration $\mathrm{H}_{\mathrm{m}}$ drops significantly compared with the lower temperature range. Analysis has also revealed that at the glass transition temperature, the viscosities of both salol and $\alpha$-phenyl-o-cresol are many orders of magnitude lower than the generically used value of $10^{12} \mathrm{~Pa} \cdot \mathrm{s}$.

Funding: This research received no external funding.

Acknowledgments: This paper is based on the invited report "Sheffield Model of Viscosity: From Douglas to Nowadays", presented at the XXV International Congress on Glass (ICG2019) held in Boston, MA, US, on 9-14 June 2019. The author is grateful to John Mauro and Vijay Jain for organization; and to Arun K. Varshneya, President of Saxon Glass Technologies, Inc., and Professor Emeritus of Glass Science and Engineering at Alfred University, US, for the invitation to participate in the Arun K. Varshneya Festschrift held at ICG2019.

Conflicts of Interest: The author declares no conflict of interest.

\section{References}

1. Volf, M.B. Mathematical Approach to Glass; Elsevier: Amsterdam, The Netherlands, 1988.

2. Stickel, F.; Fischer, E.W.; Richert, R. Dynamics of glass-forming liquids. I. Temperature-derivative analysis of dielectric relaxation data. J. Chem. Phys. 1995, 102, 6251-6257. [CrossRef]

3. Kivelson, D.; Tarjus, G.; Zhao, X.; Kivelson, S.A. Fitting of viscosity: Distinguishing the temperature dependences predicted by various models of supercooled liquids. Phys. Rev. E 1996, 53, 751-758. [CrossRef]

4. Angell, C.A.; Ngai, K.L.; McKenna, G.B.; McMillan, P.F.; Martin, S.W. Relaxation in glassforming liquids and amorphous solids. J. Appl. Phys. 2000, 88, 3113-3157. [CrossRef]

5. Doremus, R.H. Viscosity of silica. J. Appl. Phys. 2002, 92, 7619-7629. [CrossRef]

6. Tarjus, G.; Kivelson, D.; Mossa, S.; Alba-Simionesco, C. Disentangling density and temperature effects in the viscous slowing down of glassforming liquids. J. Chem. Phys. 2004, 120, 6135. [CrossRef]

7. Varshneya, A.K. Fundamentals of Inorganic Glasses; Society of Glass Technology: Sheffield, UK, 2006.

8. Ojovan, M.I.; Travis, K.P.; Hand, R.J. Thermodynamic parameters of bonds in glassy materials from viscosity-temperature relationships. J. Phys. Condens. Matter 2007, 19, 415107. [CrossRef] [PubMed]

9. Mauro, J.C.; Yue, Y.; Ellison, A.J.; Gupta, P.K.; Allan, D.C. Viscosity of glass-forming liquids. Proc. Natl. Acad. Sci. USA 2009, 106, 19780-19784. [CrossRef] [PubMed]

10. Ojovan, M. Viscous flow and the viscosity of melts and glasses. Phys. Chem. Glasses 2012, 53, $143-150$. 
11. Popova, V.A.; Surovtsev, N.V. Transition from Arrhenius to non-Arrhenius temperature dependence of structural relaxation time in glass-forming liquids: Continuous versus discontinuous scenario. Phys. Rev. E 2014, 90, 032308. [CrossRef]

12. Isayev, A.I. Encyclopedia of Polymer Blends: Volume 3: Structure, 1st ed.; Wiley-VCH: Weinheim, Germany, 2016; pp. 1-134.

13. Hrma, P.; Kruger, A.A. High-temperature viscosity of many-component glass melts. J. Non-Crystalline Solids 2016, 437, 17-25. [CrossRef]

14. Zheng, Q.; Mauro, J.C. Viscosity of glass-forming systems. J. Am. Ceram. Soc. 2016, 100, 6-25. [CrossRef]

15. Sanditov, D.S.; Ojovan, M.I. On relaxation nature of glass transition in amorphous materials. Phys. B Condens. Matter 2017, 523, 96-113. [CrossRef]

16. Starodub, K.; Wu, G.; Yazhenskikh, E.; Müller, M.; Khvan, A.; Kondratiev, A. An Avramov-based viscosity model for the $\mathrm{SiO}_{2}-\mathrm{Al}_{2} \mathrm{O}_{3}-\mathrm{Na}_{2} \mathrm{O}-\mathrm{K}_{2} \mathrm{O}$ system in a wide temperature range. Ceram. Int. 2019, 45, 12169-12181. [CrossRef]

17. Sturm, K.G. Microscopic-Phenomenological Model of Glass Transition and Molecular Translation in Liquids III.5 Viscosity Behavior and Glass Transition of Silicate Reference Glasses. Preprint, May 2020. [CrossRef]

18. Zheng, Q.; Zheng, J.; Solvang, M.; Yue, Y.; Mauro, J.C. Determining the liquidus viscosity of glass-forming liquids through differential scanning calorimetry. J. Am. Ceram. Soc. 2020. [CrossRef]

19. Chen, C.; Zeng, H.; Deng, Y.; Yan, J.; Jiang, Y.; Chen, G.; Zu, Q.; Sun, L. A Novel Viscosity-Temperature Model of Glass-Forming Liquids by Modifying the Eyring Viscosity Equation. Appl. Sci. 2020, 10, 428. [CrossRef]

20. Chevallard, G.; Samwer, K.; Zaccone, A. Atomic-scale expressions for viscosity and fragile-strong behavior in metal alloys based on the Zwanzig-Mountain formula. Phys. Rev. Res. 2020, 2, 033134. [CrossRef]

21. Tong, H.; Tanaka, H. Role of Attractive Interactions in Structure Ordering and Dynamics of Glass-Forming Liquids. Phys. Rev. Lett. 2020, 124, 225501. [CrossRef]

22. Lucas, P. Fragile-to-strong transitions in glass forming liquids. J. Non-Cryst. Solids X 2019, 4, 100034. [CrossRef]

23. Macedo, P.B.; Napolitano, A. Inadequacies of Viscosity Theories for $\mathrm{B}_{2} \mathrm{O}_{3}$. J. Chem. Phys. 1968, 49, 1887. [CrossRef]

24. Mott, N.F. The viscosity of vitreous silicon dioxide. Philos. Mag. B 1987, 56, 257-262. [CrossRef]

25. Douglas, R.W. The flow of glass. J. Soc. Glass Tech. 1949, 33, 138-162.

26. Louzguine-Luzgin, D.; Louzguina-Luzgina, L.V.; Fecht, H. On limitations of the viscosity versus temperature plot for glass-forming substances. Mater. Lett. 2016, 182, 355-358. [CrossRef]

27. Ojovan, M.I. Viscosity of network liquids within Doremus approach. J. Appl. Phys. 2004, 95, 3803. [CrossRef]

28. Ojovan, M.I.; Lee, W.E. Topologically disordered systems at the glass transition. J. Phys. Condens. Matter 2006, 18, 11507-11520. [CrossRef]

29. Trachenko, K.; Brazhkin, V.V. Minimal quantum viscosity from fundamental physical constants. Sci. Adv. 2020, 6, eaba3747. [CrossRef]

30. Ojovan, M.I. Thermodynamic Parameters of Bonds in Glassy Materials from Shear Viscosity Coefficient Data. Int. J. Appl. Glas. Sci. 2014, 5, 22-25. [CrossRef]

31. Karlsson, $\mathrm{S}$. The viscosity effect of $\mathrm{TiO}_{2}$ on soda-lime-silicate bearing glass. In Proceedings of the 4 th Workshop on Glass and Entropy and 9th Otto Schott Colloquium, Jena, Germany, 9-12 September 2019.

32. Shilov, A.L.; Saint Petersburg State University; Stolyar, S.V.; Stolyarova, V.L.; Ojovan, M.I.; Grebenshchikov Institute of Silicate Chemistry; Lomonosov Moscow State University. The viscosity of $\mathrm{Bi}_{2} \mathrm{O}_{3}-\mathrm{B}_{2} \mathrm{O}_{3}-\mathrm{SiO}_{2}$ glasses and melts. Glas. Technol. Eur. J. Glas. Sci. Technol. Part A 2019, 60, 105-110. [CrossRef]

33. Laughlin, W.T.; Uhlmann, D.R. Viscous flow in simple organic liquids. J. Phys. Chem. 1972, 76, $2317-2325$. [CrossRef]

34. Kittel, C.; Masi, J.F. Introduction to Solid State Physics. Phys. Today 1954, 7, 18. [CrossRef]

35. Richert, R. Heterogeneous dynamics in liquids: Fluctuations in space and time. J. Phys. Condens. Matter 2002, 14, R703-R738. [CrossRef]

36. Mysen, B.; Richet, P. Silicate Glasses and Melts; Elsevier: Amsterdam, The Netherlands, 2019.

37. Cukierman, M.; Lane, J.W.; Uhlmann, D.R. High-temperature flow behavior of glass-forming liquids: A free-volume interpretation. J. Chem. Phys. 1973, 59, 3639. [CrossRef]

38. Williams, M.L.; Landel, R.F.; Ferry, J.D. The Temperature Dependence of Relaxation Mechanisms in Amorphous Polymers and Other Glass-forming Liquids. J. Am. Chem. Soc. 1955, 77, 3701-3707. [CrossRef] 
39. Nemilov, S.V. Thermodynamic and Kinetic Aspects of the Vitreous State; CRC Press: Boca Raton, IL, USA, 1995.

40. Nemilov, S.V. Maxwell equation and classical theories of glass transition as a basis for direct calculation of viscosity at glass transition temperture. Glas. Phys. Chem. 2013, 39, 609-623. [CrossRef]

41. Hao, T. Unveiling the relationships among the viscosity equations of glass liquids and colloidal suspensions for obtaining universal equations with the generic free volume concept. Phys. Chem. Chem. Phys. 2015, 17, 21885-21893. [CrossRef]

42. Rault, J. The Modified VFT law of glass former materials under pressure: Part II: Relation with the equation of state. Eur. Phys. J. E 2015, 38, 91. [CrossRef] [PubMed]

43. Ojovan, M.I. About activation energy of viscous flow of glasses and melts. Mater. Res. Soc. Symp. Proc. 2015, 1757, 6. [CrossRef]

44. Mazurin, O.V. Problems of compatibility of the values of glass transition temperatures published in the world literature. Glas. Phys. Chem. 2007, 33, 22-36. [CrossRef]

45. Sanditov, D.S.; Ojovan, M.I.; Darmaev, M.V. Glass transition criterion and plastic deformation of glass. Phys. $B$ Condens. Matter 2020, 582, 411914. [CrossRef]

46. Mauro, J.C.; Smedskjaer, M.M. Statistical mechanics of glass. J. Non-Cryst. Solids 2014, 41-53. [CrossRef]

47. Tournier, R.F. Homogeneous nucleation of phase transformations in supercooled water. Phys. B Condens. Matter 2020, 579, 411895. [CrossRef]

48. Tournier, R.F. First-order transitions in glasses and melts induced by solid siperclusters nucleated and melted by homogeneous nucleation instead of surface melting. Chem. Phys. 2019, 524, 40-54. [CrossRef]

49. Ojovan, M.I.; Louzguine-Luzgin, D. Revealing Structural Changes at Glass Transition via Radial Distribution Functions. J. Phys. Chem. B 2020, 124, 3186-3194. [CrossRef] [PubMed]

50. Albert, S.; Bauer, T.; Michl, M.; Biroli, G.; Bouchaud, J.-P.; Loidl, A.; Lunkenheimer, P.; Tourbot, R.; Wiertel-Gasquet, C.; Ladieu, F. Fifth-order susceptibility unveils growth of thermodynamic amorphous order in glass-formers. Science 2016, 352, 1308-1311. [CrossRef] [PubMed]

51. Stanzione, J.; Strawhecker, K.E.; Wool, R.P. Observing the twinkling fractal nature of the glass transition. J. Non-Cryst. Solids 2011, 357, 311-319. [CrossRef]

52. Continentino, M. Topological phase transitions. Phys. B Condens. Matter 2017, 505, A1-A2. [CrossRef]

53. Angell, C.A. Configurational Excitations in Condensed Matter, and the "Bond Lattice" Model for the Liquid-Glass Transition. J. Chem. Phys. 1972, 57, 470. [CrossRef]

54. Iwashita, T.; Nicholson, D.M.; Egami, T. Elementary Excitations and Crossover Phenomenon in Liquids. Phys. Rev. Lett. 2013, 110, 205504. [CrossRef]

55. Ojovan, M.I. Ordering and structural changes at the glass-liquid transition. J. Non-Cryst. Solids 2013, 382, 79-86. [CrossRef]

56. Nemilov, S.V. On the Possibility of Calculating Entropy, Free Energy, and Enthalpy of Vitreous Substances. Entropy 2018, 20, 187. [CrossRef]

57. Cassar, D.R.; Santos, G.G.; Zanotto, E.D. Designing optical glasses by machine learning coupled with genetic algorithms. arXiv 2020, arXiv:2008.09187.

(C) 2020 by the author. Licensee MDPI, Basel, Switzerland. This article is an open access article distributed under the terms and conditions of the Creative Commons Attribution (CC BY) license (http://creativecommons.org/licenses/by/4.0/). 